\title{
Intraoperative MRI for the microsurgical resection of meningiomas close to eloquent areas or dural sinuses: patient series
}

\author{
Constantin Tuleasca, MD, PhD, ${ }^{1,3-5}$ Rabih Aboukais, MD, PhD, ${ }^{1}$ Quentin Vannod-Michel, MD, ${ }^{2}$ Xavier Leclerc, MD, ${ }^{2}$ Nicolas Reyns, MD, PhD, ${ }^{1}$ \\ and Jean-Paul Lejeune, MD, PhD'
}

\begin{abstract}
${ }^{1}$ Neurosurgery and Neurooncology Service and ${ }^{2}$ Neuroradiology Department, Lille University Hospital, Lille, France; ${ }^{3}$ Department of Clinical Neurosciences, Neurosurgery Service and Gamma Knife Center, Lausanne University Hospital, Lausanne, Switzerland; ${ }^{4}$ Faculty of Biology and Medicine, University of Lausanne, Lausanne, Switzerland; and ${ }^{5}$ Signal Processing Laboratory (LTS 5), Ecole Polytechnique Fédérale de Lausanne, Lausanne, Switzerland
\end{abstract}

BACKGROUND Meningiomas are the most commonly encountered nonglial primary intracranial tumors. The authors report on the usefulness of intraoperative magnetic resonance imaging (iMRI) during microsurgical resection of meningiomas located close to eloquent areas or dural sinuses and on the feasibility of further radiation therapy.

OBSERVATIONS Six patients benefited from this approach. The mean follow-up period after surgery was 3.3 (median 3.2, range 2.1-4.6) years. Five patients had no postoperative neurological deficit, of whom two with preoperative motor deficit completely recovered. One patient with preoperative left inferior limb deficit partially recovered. The mean interval between surgery and radiation therapy was 15.8 (median 16.9, range 1.4-40.5) months. Additional radiation therapy was required in five cases after surgery. The mean preoperative tumor volume was 38.7 (median 27.5, range 8.6-75.6) $\mathrm{mL}$. The mean postoperative tumor volume was 1.2 (median 0.8 , range $0-4.3$ ) $\mathrm{mL}$. At the last follow-up, all tumors were controlled.

LESSONS The use of iMRI was particularly helpful to (1) decide on additional tumor resection according to iMRI findings during the surgical procedure; (2) evaluate the residual tumor volume at the end of the surgery; and (3) judge the need for further radiation and, in particular, the feasibility of single-fraction radiosurgery.

https://thejns.org/doi/abs/10.3171/CASE20149

KEYWORDS intraoperative; meningioma; magnetic resonance imaging; radiation; radiosurgery; Gamma Knife

Meningiomas are the most commonly encountered nonglial primary intracranial tumors, with an incidence of approximately $20 \%$ of all intracranial tumors. ${ }^{1}$ They are more frequent in adults during the fourth through sixth decades of life. ${ }^{2,3}$ The clinical presentation is variable, unspecific, and depends on tumor anatomical location. ${ }^{1}$ Magnetic resonance imaging (MRI) is currently considered the imaging technique of choice and allows assessment of potential mass effect, vascular supply, or degree of the peritumoral edema, as well as accurate localization of meningioma. ${ }^{4}$ Some authors have suggested a role for intraoperative MRI (iMRI) in the context of tailored patient management. ${ }^{5}$

First-line therapy includes "wait-and-scan" observation, microsurgical resection, ${ }^{6}$ or radiosurgery. ${ }^{7}$ For patients who are considered surgical candidates (those with surgically accessible lesions), the goal is complete/gross-total microsurgical resection according to the Simpson grade, as this is the most important factor influencing recurrence. 8,9 The use of radiation therapy and, particularly, stereotactic radiosurgery (SRS) can be considered as an upfront therapeutic approach following partial resection or for atypical or malignant meningiomas. ${ }^{7,10,11}$ In such instances, iMRI could help to determine the extent of resection (EOR). Moreover, and whenever necessary, it also allows evaluation of the new anatomical relationships with surrounding anatomical structures, both vascular and functional. Thus, it may help in decision-making with regard to the feasibility of combined approaches with adjuvant SRS ${ }^{12,13}$ or fractionated radiotherapy (FRT) while decreasing mortality and morbidity and preserving quality of life. The wellknown risks for adjuvant SRS are mainly related to the volume of the lesion, the anatomical location, and the delivered dose. ${ }^{14}$

ABBREVIATIONS ARE = adverse radiation event; DTI = diffusion tensor imaging; EOR = extent of resection; $f M R I=$ functional MRI; FRT = fractionated radiotherapy; GK = Gamma Knife; iMRI = intraoperative MRI; MRI = magnetic resonance imaging; OR = operating room; SRS = stereotactic radiosurgery; WHO = World Health Organization. INCLUDE WHEN CITING Published February 22, 2021; DOI: 10.3171/CASE20149.

SUBMITTED December 10, 2020. ACCEPTED December 11, 2020.

(c) 2021 The authors, CC BY-NC-ND 4.0 (http://creativecommons.org/licenses/by-nc-nd/4.0/). 
Complete microsurgical resection can be curative.,3,8,9,15 In an attempt to enhance anatomical location and resection, it has been previously proposed to introduce iMRI, ${ }^{16,17}$ particularly for patients harboring intracranial meningiomas in proximity to eloquent areas (e.g., motor related, rolandic, speech related, or Broca) ${ }^{18}$ or those invading major dural venous sinuses. ${ }^{19,20}$ Such anatomical locations can be at risk for higher postoperative deficits but also for harboring tumor remnants after surgery, potentially leading to further recurrences.

Here, we present the combined use of iMRI and microsurgical resection, followed or not by radiation therapy, depending on tailored patient management. The primary research question was whether iMRI could help with deciding on additional tumor resection and evaluating residual tumor at the end of surgery, as well as the feasibility of further radiation and, in particular, single-fraction SRS.

\section{Study Description}

\section{Patient Population}

Starting November 2016 through November 2020, six patients benefited from iMRI and microsurgical resection. There was no patient lost to follow-up. All patients were operated on by the senior neurosurgeon (J-P.L.). Although we had planned to perform iMRI in the dedicated operating room $(\mathrm{OR})$ on one patient, the imaging was unnecessary because complete microsurgical resection had been successful and there was no doubt regarding any potential tumor remnant.

The inclusion criteria were as follows: patients with intracranial meningioma suspected on preoperative MRI, independent of age, with microsurgical resection in the iMRI setting and OR. Exclusion criteria were an inability to provide informed consent and the absence of an iMRI procedure.

Basic demographic data can be seen in Table 1. The female-to-male ratio was 4:2. The tumor location was as follows: convexity, in proximity to the rolandic area $(n=4)$; convexity, in proximity to the Broca area $(n=1)$; and parasagittal with invasion of the superior sagittal sinus $(n=1)$. The mean age at the time of surgery was 58.4 (median 60.6, range 46.9-69.7) years. The context of preoperative discovery was paresthesias $(n=1)$, inferior limb deficit $(n=2)$, hemiparesis $(n=1)$, or incidental $(n=2)$.

\section{Preoperative MRI}

Preoperative MRI included, besides standard assessment, diffusion tractography (diffusion tensor imaging [DTI]) and tasked-based functional MRI (fMRI), whenever necessary, as depending on the anatomical location.

\section{Intraoperative Imaging Using iMRI}

Patients benefitted from intraoperative 1.5 tesla MRI (General Electric). We used an MRI-compatible head holder to position the patient. The imaging sequences for neuronavigation were three-dimensional turbo-spin echo T1 with and without gadolinium injection. Before moving patients into the MRI, a checklist was systematically completed to ensure the absence of metallic material on the surgical site that could potentially interfere with the magnetic field. The neuronavgation data update procedure was performed using the automatic coregistration provided by Brainlab (Brainlab AG). The quality and accuracy of the coregistration were double-checked by an imaging engineer and board-certified neurosurgeon. ${ }^{21}$ We always discussed the MRI with our neuroradiologist so as to evaluate the EOR and other surgery-related aspects. The surgical microscope (OPMI Pentero; Zeiss) was connected to the imaging network and could be used as neuronavigation.

\section{Volumetric Measurements}

Volumetric measurements were performed with the Leksell Gamma Plan software (Elekta Instruments $A B$ ), using both pre- and postoperative T1weighted gadolinium-injected MR sequences (1-mm slices). The module automatic segmentation using a standard contrast amount was initially used. The first volume draft was further refined using manual drawing.

\section{Basic Pre- and Postoperative Volumetric Data and Histopathological Diagnosis}

Basic volumetric data can be seen in Table 2. The mean preoperative tumor volume was 38.7 (median 27.5, range 8.6-75.5) mL.

TABLE 1. Basic demographic data

\begin{tabular}{|c|c|c|c|c|c|c|c|c|c|c|}
\hline $\begin{array}{l}\text { Case } \\
\text { No. }\end{array}$ & Sex & Side & Location & $\begin{array}{c}\text { Neurological } \\
\text { Function at } \\
\text { Discovery }\end{array}$ & $\begin{array}{l}\text { Age at } \\
\text { Surgery } \\
\text { (yrs) }\end{array}$ & $\begin{array}{c}\text { Age at } \\
\text { GK/RT } \\
\text { (yrs) }\end{array}$ & $\begin{array}{c}\text { Interval Btwn } \\
\text { Surgery \& } \\
\text { Radiation (mos) }\end{array}$ & $\begin{array}{c}\text { Neurological Outcome } \\
\text { After Surgery }\end{array}$ & $\begin{array}{c}\text { FU After } \\
\text { Surgery; } \\
\text { Radiation (yrs) }\end{array}$ & $\begin{array}{l}\text { WHO } \\
\text { Grade }\end{array}$ \\
\hline 2 & $\mathrm{~F}$ & $\mathrm{Lt}$ & $\begin{array}{l}\text { Parasagittal } \\
\text { (SSS) }\end{array}$ & Incidental & 47.1 & $\begin{array}{l}48.6 \\
(G K)\end{array}$ & 18.3 & No deficit & $3.4 ; 1.9$ & 1 \\
\hline 3 & $\mathrm{~F}$ & $\mathrm{Lt}$ & $\begin{array}{c}\text { Convexity } \\
\text { (language area) }\end{array}$ & Incidental & 46.9 & 47 (GK) & 1.4 & No deficit & $4.6 ; 4.5$ & 1 \\
\hline 4 & $\mathrm{~F}$ & $\mathrm{Rt}$ & $\begin{array}{c}\text { Convexity } \\
\text { (rolandic area) }\end{array}$ & Lt hemiparesis & 58.1 & $\begin{array}{l}58.3 \\
\text { (RT) }\end{array}$ & 1.9 & $\begin{array}{l}\text { No deficit (complete } \\
\text { recovery) }\end{array}$ & $2.1 ; 2$ & II \\
\hline 5 & $\mathrm{~F}$ & $\mathrm{Lt}$ & $\begin{array}{c}\text { Convexity } \\
\text { (rolandic area) }\end{array}$ & $\begin{array}{l}\text { Rt inferior limb } \\
\text { deficit }\end{array}$ & 69.7 & $\mathrm{~N} / \mathrm{A}$ & $\mathrm{N} / \mathrm{A}$ & $\begin{array}{l}\text { No deficit (complete } \\
\text { recovery) }\end{array}$ & $3 ; N / A$ & 1 \\
\hline
\end{tabular}

FU = follow-up; N/A = not applicable; RT = radiotherapy; SSS = superior sagittal sinus 
TABLE 2. Basic dosimetric and volumetric data, including at last follow-up

\begin{tabular}{|c|c|c|c|c|c|c|c|c|}
\hline $\begin{array}{l}\text { Case } \\
\text { No. }\end{array}$ & $\begin{array}{c}\text { Preop } \\
\text { Vol (mL) }\end{array}$ & $\begin{array}{c}\text { Immediate Postop } \\
\text { Vol (mL) }\end{array}$ & $\begin{array}{l}\text { Late Postop Vol in } \mathrm{mL} \\
\text { (yrs since surgery for the } \\
\text { growing residual tumor) }\end{array}$ & $\begin{array}{l}\text { WHO } \\
\text { Grade }\end{array}$ & GK/RT & Radiation Dose & Vol at Radiation (mL) & $\begin{array}{l}\text { Vol at Last FU (mL); } \\
\text { Yrs Since Radiation }\end{array}$ \\
\hline 1 & 17.6 & 1.4 & $3.1(3)$ & 1 & GK & 14 Gy at $50 \%$ & 5.2 & $2.8 ; 1$ \\
\hline 2 & 19.4 & 1.5 & 1.5 & 1 & GK & 15 Gy at $50 \%$ & 1.6 & $1.4 ; 1.9$ \\
\hline 3 & 35.7 & $\mathrm{~N} / \mathrm{A}$ & 0.7 & I & GK & 14 Gy at $50 \%$ & 0.7 & $0.1 ; 4.5$ \\
\hline 4 & 75.6 & 0.2 & 0.2 & II & RT & $54 \mathrm{~Gy}$ & 0.2 & $0.2 ; 2$ \\
\hline 5 & 8.6 & 0.01 & 0.01 & 1 & $\mathrm{~N} / \mathrm{A}$ & $\mathrm{N} / \mathrm{A}$ & $\mathrm{N} / \mathrm{A}$ & $\mathrm{N} / \mathrm{A}$ \\
\hline 6 & 75.5 & 4.3 & 4.3 & II & RT & 36 Gy in 9 fractions & 4.3 & $4.3 ; 1$ \\
\hline
\end{tabular}

The mean postoperative tumor volume was 1.2 (median 0.8 , range $0-4.3) \mathrm{mL}$. The World Health Organization (WHO) classification was grade I for four cases and grade II for two cases.

\section{Radiation Therapy Details and Follow-Up Course}

Postoperative radiation after surgery was performed in five cases. Of these, three involved single-fraction Gamma Knife (GK) $4 \mathrm{C}$ and later ICON models (Elekta Instruments $\mathrm{AB}$ ) for WHO grade $\mathrm{I}$, and two involved FRT for WHO grade II. One WHO grade I meningioma did not benefit from adjuvant radiation therapy due to a stable minimal residual tumor volume. For single-fraction SRS, the marginal dose prescribed was $14 \mathrm{~Gy}(\mathrm{n}=2)$ or $15 \mathrm{~Gy}(\mathrm{n}=1)$ at the $50 \%$ isodose line. For FRT, one patient received $54 \mathrm{~Gy}$ while the other had $36 \mathrm{~Gy}$ in 9 fractions. The mean tumor volume at the time of radiation was 2.4 (median 1.6, range $0.2-5.2) \mathrm{mL}$. The mean volume at the last followup was 1.8 (median 1.6 , range $0.1-4.3$ ) $\mathrm{mL}$.

\section{Follow-Up Period After Surgery}

The mean follow-up period after surgery was 3.3 (median 3.2, range 2.1-4.6) years.

\section{Neurological Evaluation After Surgery}

Five patients had no postoperative neurological deficit, of whom two with preoperative motor deficit completely recovered (cases 5 and 6 ). One patient with preoperative left inferior limb deficit partially recovered (case 6, Table 1).

\section{Interval Between Surgery and Radiation Therapy}

The mean interval between surgery and radiation therapy was 15.8 (median 16.9, range 1.4-40.5) months.

\section{Follow-Up Period After Radiation}

The mean follow-up period after radiation was 2.1 (median 1.9, range 1-4.5) years.

\section{Tumor Control at Last Follow-Up}

At the last follow-up, all tumors were controlled.

\section{Illustrative Case 3 Benefiting From iMRI and Combined Approach}

A 47-year-old female presented to our outpatient clinic with an incidentally discovered left convexity meningioma close to the language areas (left Broca, Fig. 1A). In this ambidextrous patient, preoperative fMRI revealed bilateral language activation with left dominance (Fig. 1A). The preoperative tumor volume was $35.7 \mathrm{~mL}$ (Fig. 1B).
Gross-total microsurgical resection (Fig. 1C) was performed, with further iMRI during surgery (Fig. 2A). The former confirmed a small residual tumor compatible with adjuvant GK surgery, which was then performed on a volume of $0.7 \mathrm{~mL}$ with a dose of $14 \mathrm{~Gy}$ at the $50 \%$ isodose line (Fig. 2B).

At the last follow-up 4 years after GK surgery, the tumor decreased in size, passing from $0.7 \mathrm{~mL}$ to $0.1 \mathrm{~mL}$. The patient was neurologically intact (Fig. 2C).

\section{Illustrative Case 2 Benefiting From iMRI and Combined Approach}

A 45-year-old female presented with a left parasagittal meningioma, with invasion of the superior sagittal sinus (Fig. $3 \mathrm{~A}$, volume $=19.4 \mathrm{~mL}$ ). A gross-total resection was later performed, with iMRI showing minimal residual tumor (Fig. 3B). MRI 6 months after surgery and another 16 months later displayed a volumetric increase (Fig. $3 \mathrm{C}$ ); the patient underwent GK surgery with a dose of $15 \mathrm{~Gy}$ at the $50 \%$ isodose line on a volume of $1.6 \mathrm{~mL}$ (Fig. 4A). Two years after GK surgery, follow-up MRI showed volumetric decrease (Fig. 4B, volume $=1.4 \mathrm{~mL}$ ).

Illustrative Case With Initial Decision but No Further iMRI Need

A 37-year-old female presented with a left frontal anterior parasagittal meningioma incidentally discovered (Fig. $5 \mathrm{~A}$ and $\mathrm{B}$ ) close to the motor strip (Fig. 5A left, DTI showing the pyramidal tract in blue) and the language areas (Fig. 5A right, fMRI). IMRI was initially scheduled during resection. However, there was a clear cleavage plane and no intraoperative residual tumor. The intraoperative macroscopic aspect (Fig. 5C) suggested total resection. We did not perform iMRI as it was not necessary.

\section{Discussion \\ Observations}

The present study evaluates the benefit and feasibility of the combined use of microsurgical resection and iMRI for meningiomas close to eloquent areas or major dural sinuses. Of note, our neurosurgical setting benefits from both an iMRI and an SRS unit (GK, Elekta Instruments $\mathrm{AB}$ ). First, we consider the presurgical detailed neuroimaging evaluation as mandatory. Several factors can suggest the feasibility of complete microsurgical resection, depending on whether a potential cleavage plane is present. The three key factors are a T2 cleft sign, ${ }^{22}$ meningioma volume ${ }^{23}$ on preoperative MRI, and significant corticopial vascularization on preoperative digital subtraction angiography. ${ }^{24}$ Moreover, larger meningiomas would tend to potentially infiltrate the arachnoidal plane more frequently than the smaller ones, therefore causing edema and resulting in the lack of a cleavage plane. ${ }^{18} \mathrm{We}$ 

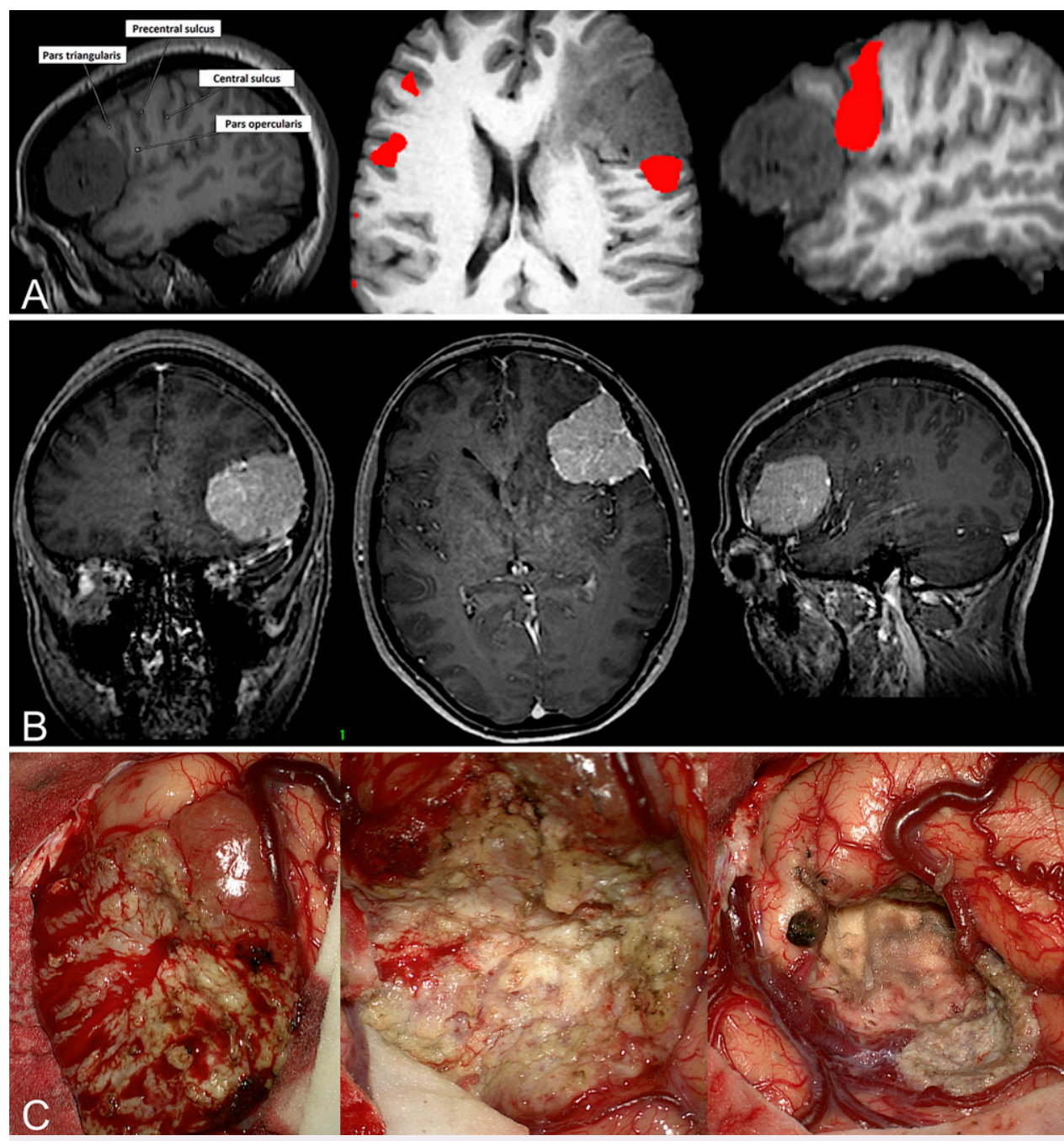

FIG. 1. Illustration of a combined approach and using iMRI (case 3). A: Convexity meningioma close to the pars triangularis and opercularis, found at the posterosuperior pole of the tumor. B: MRI before surgery, reconstructed in the coronal, axial, and sagittal planes (tumor volume $=35.7 \mathrm{~mL}$ ). C: Intraoperative macroscopic aspect at the beginning of the surgery (left, center) and at the end of the surgery (right).

complete the neuroimaging assessment with DTI or $\mathrm{FMRI}$ whenever necessary, depending on the exact anatomical location. Here, we discuss the combined use of iMRI and microsurgical resection, followed or not by radiation therapy, depending on tailored patient management. iMRI was, in our experience, particularly useful to evaluate the volume residue (if any) to be able to continue microsurgical resection while using up-to-date images or to evaluate a particular anatomical relationship (mainly vascular). In our opinion, such aspects could enhance the preservation of neurological function and thus quality of life.

\section{Convexity Meningiomas Located Within the Rolandic Area}

Convexity meningiomas located within the rolandic areas pose specific microsurgical issues. As opposed to classic convexity meningiomas, which only require a rather low-risk procedure,,$^{25}$ they may engender postoperative motor deficits with a risk ranging between $7.1 \%$ and $24.7 \%{ }^{26}$ of cases. ${ }^{18}$ Moreover, such risks become higher when a clear arachnoidal cleavage plane with the motor pathway (e.g., corticospinal tract and the primary motor cortex) is not directly identifiable. Thus, combined strategies using a wide range of techniques have been reported, including preoperative DTI, ${ }^{18}$ navigated transcranial magnetic stimulation, ${ }^{27}$ or intraoperative neurophysiological mapping, with the latter rarely discussed for rolandic meningiomas and with questionable usefulness. ${ }^{26}$ In fact, all these techniques have their pitfalls and challenges. We consider the use of iMRI particularly useful in this anatomical location, especially for evaluating the anatomical relationship with the primary motor cortex but also for volumetric issues. Moreover, iMRI particularly helps to decide on additional tumor resection according to its findings during the surgical procedure, evaluate the residual tumor volume at the end of the surgery, and judge the need for further radiation and, in particular, the feasibility of single-fraction radiosurgery.

\section{Meningiomas Involving Major Dural Sinuses}

Concerning the surgical management of meningiomas involving major dural sinuses, the great surgical dilemma is whether the surgeon should leave a residual tumor fragment or perform complete microsurgical 

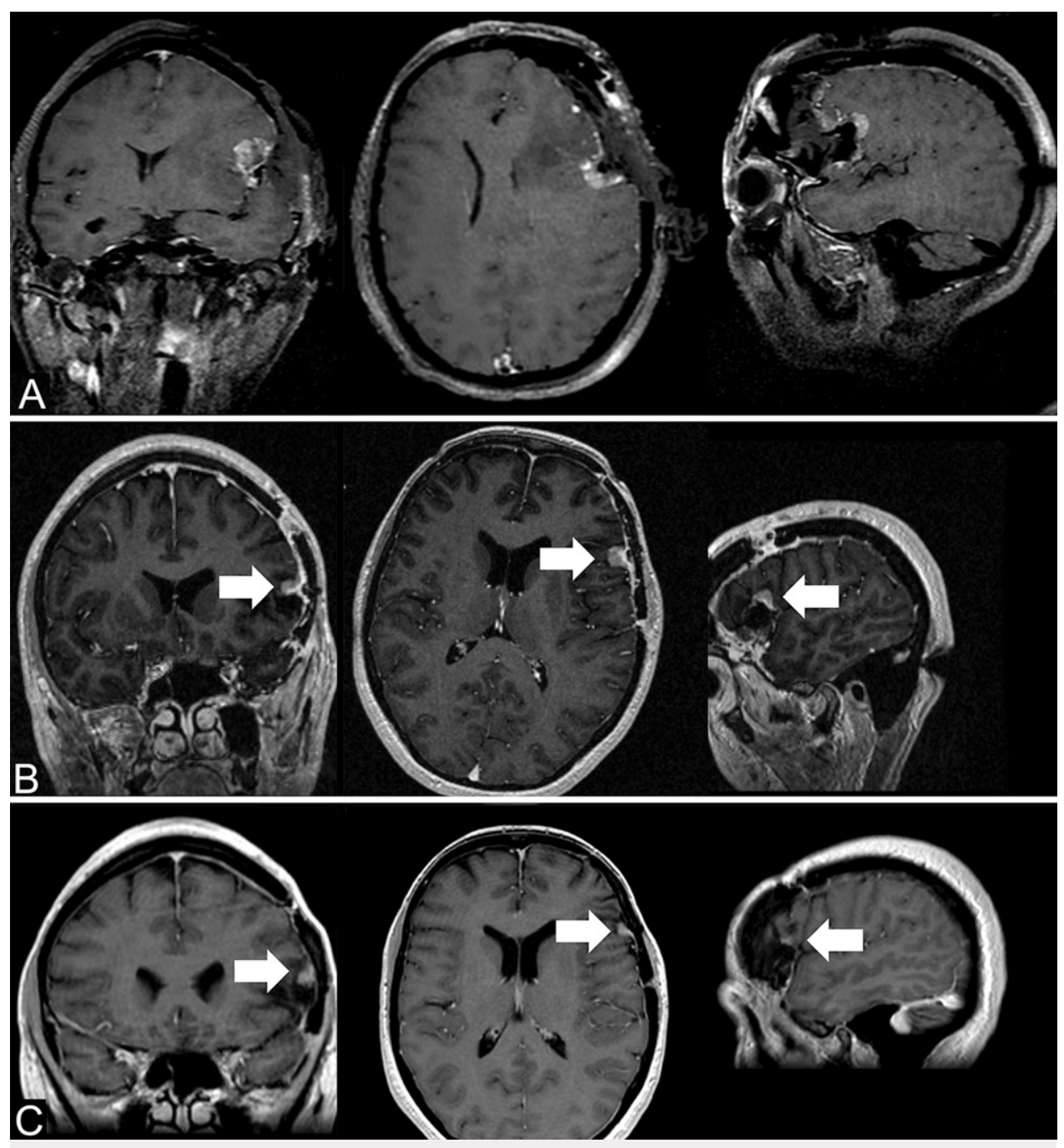

FIG. 2. Illustration of a combined approach and using iMRI (case 3). A: Convexity meningioma close to the pars triangularis and opercularis on $\mathrm{MRI}$, showing minimal residual tumor, reconstructed in the coronal, axial, and sagittal planes. B: MRI at the time of GK surgery, which was 2 months after surgery, reconstructed in the coronal, axial, and sagittal planes (tumor volume $=0.7 \mathrm{~mL}$ ). C: MRI 4 years after GK surgery, reconstructed in the coronal, axial, and sagittal planes (tumor volume $=0.1 \mathrm{~mL}$ ). Arrows point out the residual meningioma after surgery at the time of GK (B) and at last follow-up (C).

resection, with a risk for the venous circulation. ${ }^{20}$ Such a residual meningioma would result in higher tumor recurrence. ${ }^{9}$ Several approaches have been discussed over the years, including resecting the tumor outside the sinus wall and coagulating the remnant with or without en bloc removal of the residual fragment if the sinus is already occluded. ${ }^{28}$ However, complete removal and eventual venous infarcts could place patients at risk for major postoperative neurological deficits, impairing quality of life $e^{20,29}$ or even causing death, according to some series, ${ }^{20}$ if performing aggressive resection. In a recent paper ${ }^{20}$ whose authors also performed a systematic review of meningiomas involving major dural sinuses and reconstruction procedures, the recurrence rate ranged between $4 \%$ and $23.9 \%$ after a median follow-up of between 5 and 13 years; the overall mortality was between $0 \%$ and $12.3 \%{ }^{20}$ These risks are also related to sacrificing cortical bridging veins with further venous engorgement and decrease in vascular flow, with venous stasis and eventual thrombosis. On the other hand, subtotal resection without radiation poses the challenge of later tumor recurrence. ${ }^{30}$ Thus, there is a need to develop new treatment paradigms, aiming at preserving neurological function. Among those, SRS has been suggested to prevent tumor recurrence or regrowth. ${ }^{31,32}$

\section{Combined Approaches With Planned Subtotal Resection Followed by Radiosurgery}

During the past years, combined approaches with postoperative adjuvant radiosurgery on the postoperative residual tumors have been proposed, ${ }^{33}$ aiming at conserving neurological function. ${ }^{34-36}$ Such approaches depend mainly on the residual tumor volume to safely perform SRS as an adjuvant therapy. ${ }^{37}$ Long-term tumor control after SRS also depends on histology, being as high as $93 \%-95 \%$ for WHO grade I, $50 \%-60 \%$ for WHO grade II, and decreasing to $10 \%-17 \%$ for WHO grade III. ${ }^{38}$ Concerning WHO grade I meningiomas, $40 \%-80 \%$ will shrink by approximately $25 \%-40 \%$ of volume after SRS during the 

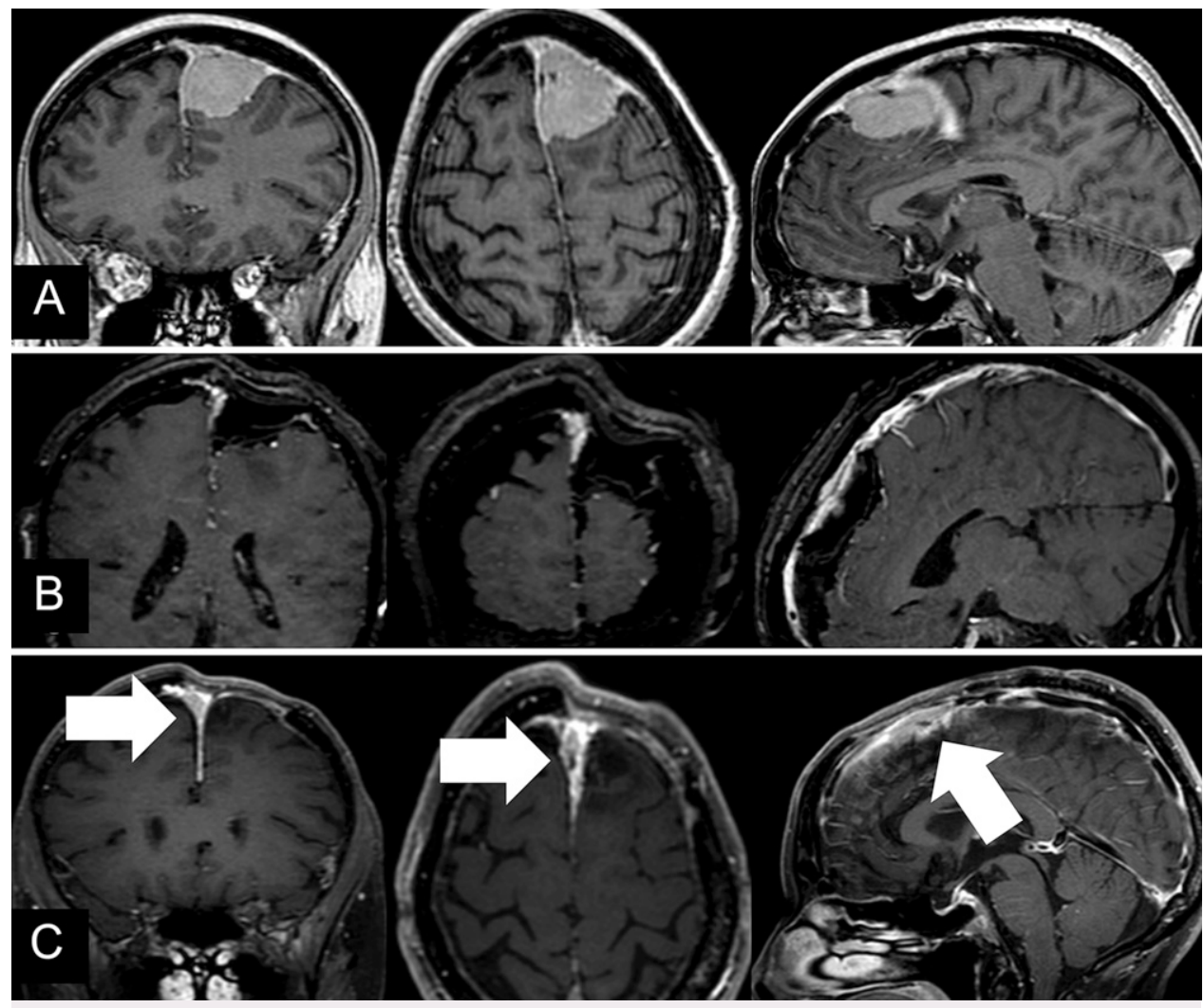

FIG. 3. Illustration of a combined approach and using iMRI (case 2). A: Preoperative MRI reconstructed in the coronal, axial, and sagittal planes and showing a left parasagittal meningioma invading the superior sagittal sinus (lesion volume $19.4 \mathrm{~mL}$ ). B: iMRI reconstructed in the coronal, axial, and sagittal planes (lesion volume $=1.4 \mathrm{~mL}$ ). C: MRI 6 months after surgery (arrows show the residual meningioma).
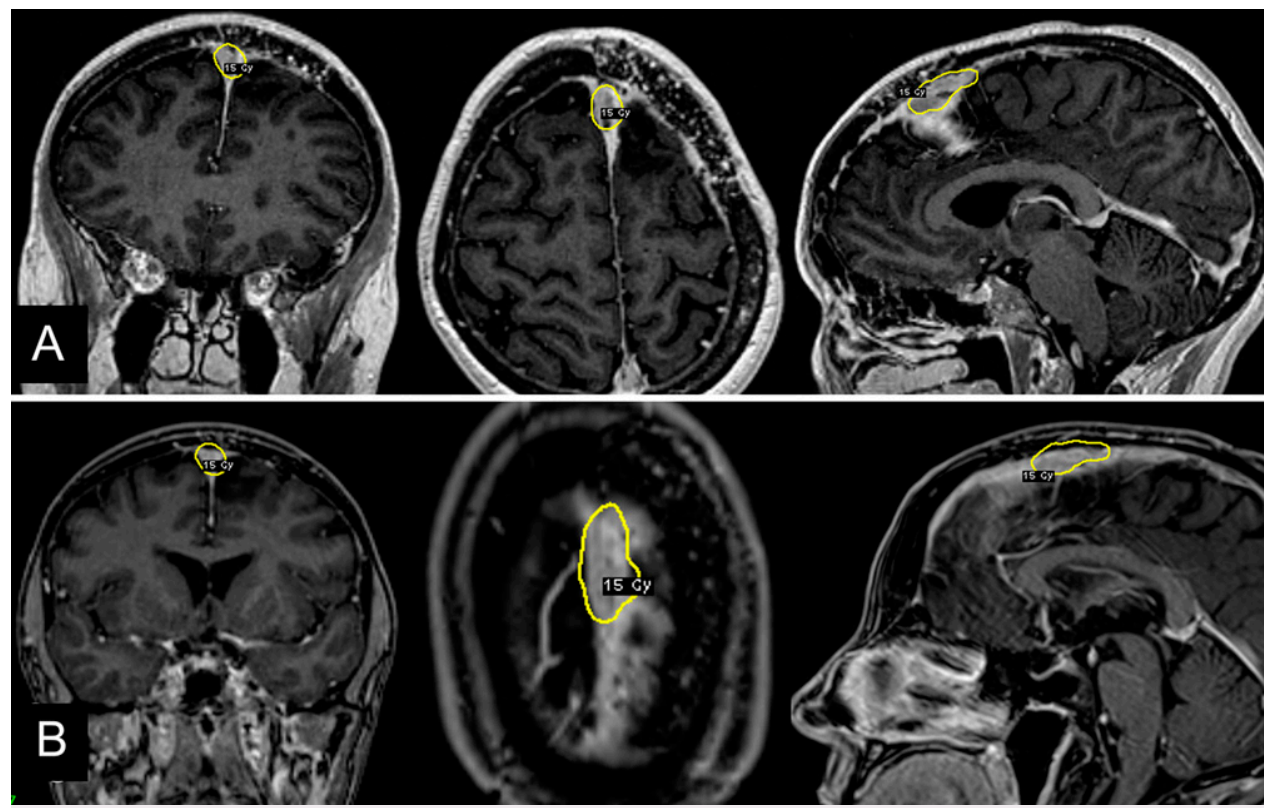

FIG. 4. Illustration of a combined approach and using iMRI (case 2). A: MRI at the time of GK surgery, with superimposed dosimetry in yellow, 16 months after surgery (lesion volume $=1.6 \mathrm{~mL}$ ). B: MRI 2 years after GK surgery, with superimposed dosimetry in yellow (lesion volume $=1.4 \mathrm{~mL}$ ). 

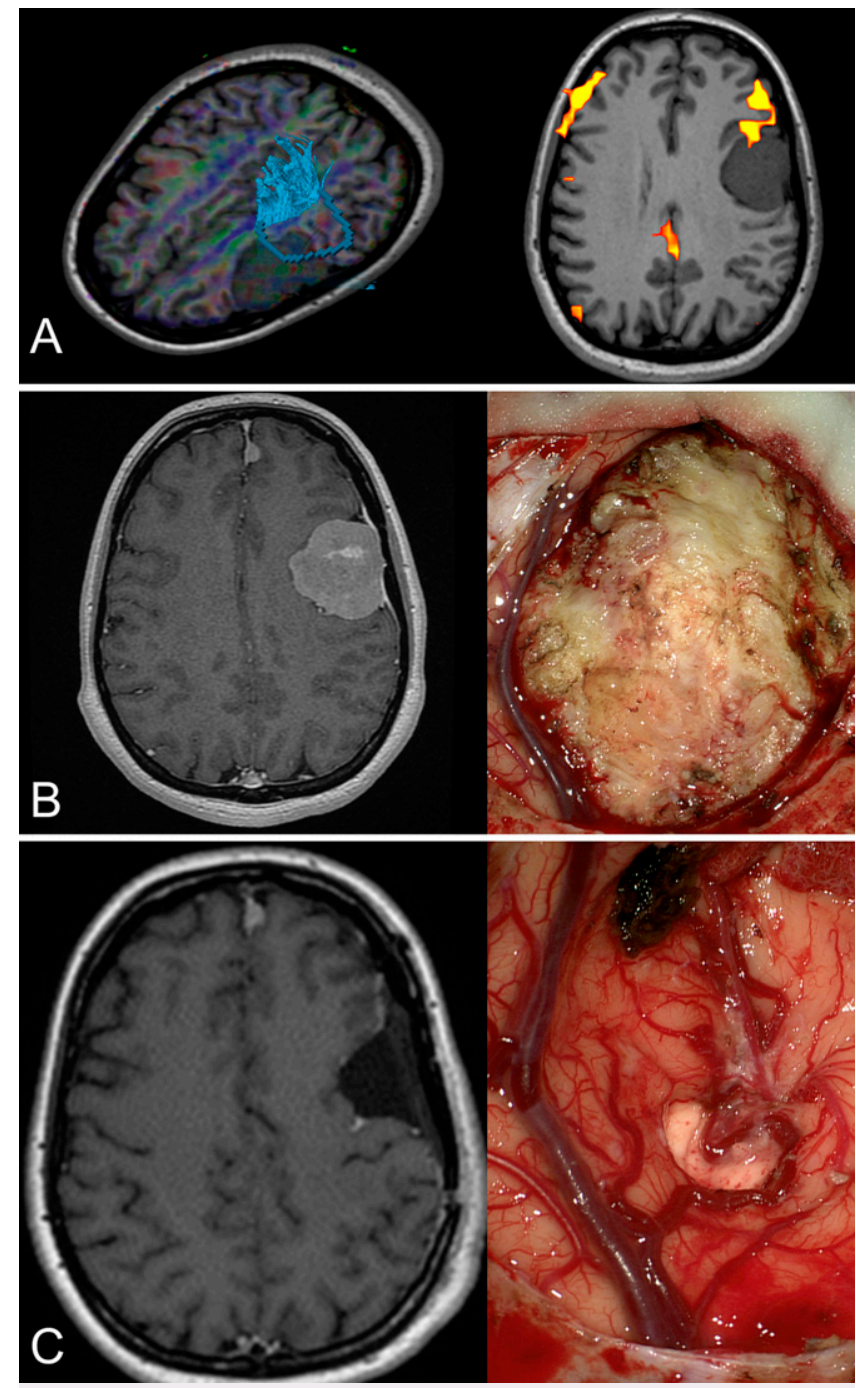

FIG. 5. Illustration of complete microsurgical resection and no need for iMRI. A: MRI before microsurgical resection (left, tractography; right, fMRI), which was scheduled for the OR using iMRI. B: T1-weighted MRI before surgery (left) and the intraoperative aspect at the beginning of surgery (right). C: MRI after surgery (left) and the intraoperative aspect at the end of surgery showing complete microsurgical resection (right).

follow-up course. In summary, most of the published series report excellent results on tumor control for WHO grade I meningiomas, ranging between $86.7 \%{ }^{39}$ and $100 \% .40,41$ An important aspect, illustrated by Zachenhofer et al., ${ }^{42}$ is that patients could be "late responders" with a tumor starting to shrink beyond 4 years after SRS. Radiosurgery has also a risk of symptomatic imaging-demonstrated changes, which are frequently transient. ${ }^{36}$ The risk of such adverse radiation events (AREs) after SRS is mostly related to symptomatic edema or damage to the cranial nerves. In a recent meta-analysis, ${ }^{43}$ which included 4229 patients, the overall relative frequency of AREs was $8.1 \%$ (range $5.2 \%-11.5 \%$ ). In the vast majority of cases, the morbidity was transient and rarely disabling. Permanent complications have been reported in only to $2.5 \%$ to $9 \%$ of cases. The optimal SRS marginal prescribed dose is still a matter of debate in the current literature. Usually, dose prescription depends on tumor volume, surrounding risk structures (such as the optic nerve, cochlea), and histology (if available at the time of SRS). It is currently commonly considered that marginal doses below $12 \mathrm{~Gy}$ are associated with further tumor growth. ${ }^{44}$ Moreover, doses of more than 15 Gy do not enhance tumor control for WHO grade I meningiomas. ${ }^{45}$

\section{Limitations}

Our case series has several inherent limitations. The first is the low number of cases in which such an approach was considered. The second is related to the timing of iMRI use during surgery, which we leave until the moment when we consider resection as reasonably complete without excessive surgical risk. However, such evaluation remains very subjective, and it may be difficult to visually assess the residual volume during surgery using visual inspection only and, furthermore, to decide the exact timing of iMRI. The third is the timing of radiosurgery or FRT. In the present series, only one case did not benefit from adjuvant treatment given a minimal and stable postoperative residue.

\section{Lessons}

Combined approaches with subtotal/gross-total resection followed by SRS are appealing in order to preserve a patient's neurological function and thus their quality of life. Such a treatment paradigm should be based on tailored management. The use of iMRI was particularly helpful to (1) decide on additional tumor resection according to iMRI findings during the surgical procedure, (2) evaluate the residual tumor volume at the end of the surgery, and (3) judge the need for further radiation and, in particular, the feasibility of single-fraction radiosurgery. However, iMRI should be used carefully and not dogmatically as it is a powerful, yet one of many, neurosurgical tools.

\section{Acknowledgments}

Constantin Tuleasca gratefully acknowledges receipt of a Young Researcher in Clinical Research Grant (Jeune Chercheur en Recherche Clinique) from the University of Lausanne, Faculty of Biology and Medicine, and the Lausanne University Hospital.

\section{References}

1. Rockhill J, Mrugala M, Chamberlain MC. Intracranial meningiomas: an overview of diagnosis and treatment. Neurosurg Focus. 2007;23(4):E1.

2. Bondy M, Ligon BL. Epidemiology and etiology of intracranial meningiomas: a review. J Neurooncol. 1996;29(3):197-205.

3. De Monte F. Current management of meningiomas. Oncology (Williston Park). 1995;9(1):83-91, 96, 99-101.

4. Watts J, Box G, Galvin A, et al. Magnetic resonance imaging of meningiomas: a pictorial review. Insights Imaging. 2014;5(1): 113-122.

5. Huang RY, Bi WL, Griffith B, et al. Imaging and diagnostic advances for intracranial meningiomas. Neuro Oncol. 2019; 21(1)(suppl 1):i44-i61.

6. Apra C, Peyre M, Kalamarides M. Current treatment options for meningioma. Expert Rev Neurother. 2018;18(3):241-249.

7. Kondziolka D, Mathieu D, Lunsford LD, et al. Radiosurgery as definitive management of intracranial meningiomas. Neurosurgery. 2008;62(1):53-60.

8. Mirimanoff RO, Dosoretz DE, Linggood RM, et al. Meningioma: analysis of recurrence and progression following neurosurgical resection. J Neurosurg. 1985;62(1):18-24.

9. Schwartz TH, McDermott MW. The Simpson grade: abandon the scale but preserve the message. J Neurosurg. Published online October 9, 2020. doi:10.3171/2020.6.JNS201904

10. Lee CC, Trifiletti DM, Sahgal A, et al. Stereotactic radiosurgery for benign (World Health Organization grade I) cavernous sinus 
meningiomas-International Stereotactic Radiosurgery Society (ISRS) practice guideline: a systematic review. Neurosurgery. 2018;83(6):1128-1142.

11. Marchetti M, Sahgal A, De Salles AAF, etal. Stereotactic radiosurgery for intracranial noncavernous sinus benign meningioma: International Stereotactic Radiosurgery Society systematic review, metaanalysis and practice guideline. Neurosurgery. 2020;87(5):879-890.

12. Daniel RT, Tuleasca $C$, George $M$, et al. Preserving normal facial nerve function and improving hearing outcome in large vestibular schwannomas with a combined approach: planned subtotal resection followed by Gamma Knife radiosurgery. Acta Neurochir (Wien). 2017;159(7):1197-1211.

13. Starnoni D, Daniel RT, Tuleasca $C$, et al. Systematic review and meta-analysis of the technique of subtotal resection and stereotactic radiosurgery for large vestibular schwannomas: a "nervecentered" approach. Neurosurg Focus. 2018;44(3):E4.

14. Chang JH, Chang JW, Choi JY, et al. Complications after Gamma Knife radiosurgery for benign meningiomas. J Neurol Neurosurg Psychiatry. 2003;74(2):226-230.

15. Saraf S, McCarthy BJ, Villano JL. Update on meningiomas. Oncologist. 2011;16(11):1604-1613.

16. Adeolu AA, Sutherland GR. Intraoperative magnetic resonance imaging and meningioma surgery. West Afr J Med. 2006;25(3):174-178.

17. Chakraborty S, Zavarella S, Salas S, et al. Intraoperative MRI for resection of intracranial meningiomas. J Exp Ther Oncol. 2017; 12(2):157-162.

18. Raffa G, Picht T, Scibilia A, et al. Surgical treatment of meningiomas located in the rolandic area: the role of navigated transcranial magnetic stimulation for preoperative planning, surgical strategy, and prediction of arachnoidal cleavage and motor outcome. J Neurosurg. 2020;133(1):107-118.

19. Han MS, Kim YJ, Moon KS, et al. Lessons from surgical outcome for intracranial meningioma involving major venous sinus. Medicine (Baltimore). 2016;95(35):e4705.

20. Sindou MP, Alvernia JE. Results of attempted radical tumor removal and venous repair in 100 consecutive meningiomas involving the major dural sinuses. J Neurosurg. 2006;105(4):514-525.

21. Leroy HA, Delmaire $C$, Le Rhun $E$, et al. High-field intraoperative MRI and glioma surgery: results after the first 100 consecutive patients. Acta Neurochir (Wien). 2019;161(7):1467-1474.

22. Takeguchi T, Miki H, Shimizu T, et al. Prediction of tumor-brain adhesion in intracranial meningiomas by MR imaging and DSA. Magn Reson Med Sci. 2003;2(4):171-179.

23. Ottenhausen M, Rumalla K, Younus I, et al. Predictors of postoperative motor function in rolandic meningiomas. J Neurosurg. Published online May 25, 2018. doi:10.3171/2017.12.JNS172423

24. Kozler P, Benes V, Netuka D, et al. Intracranial meningioma surgery outcome-the impact of preoperative neuroimaging. Prague Med Rep. 2006;107(3):327-334.

25. Sanai N, Sughrue ME, Shangari G, et al. Risk profile associated with convexity meningioma resection in the modern neurosurgical era. J Neurosurg. 2010;112(5):913-919.

26. Ostrý $S$, Netuka $D$, Beneš $V$. Rolandic area meningioma resection controlled and guided by intraoperative cortical mapping. Acta Neurochir (Wien). 2012;154(5):843-853.

27. Rizzo V, Terranova C, Conti A, etal. Preoperative functional mapping for rolandic brain tumor surgery. Neurosci Lett. 2014;583:136-141.

28. Levoshko LI, Voĭnov VI, Korotin VS. Experience with surgery of parasagittal meningioma. Article in Russian. Vopr Onkol. 1999; 45(5):520-522.

29. Gagibov GA, Karaseva TA, Kuklina AS, et al. Disorders of motor functions after removal of parasagittal meningiomas. Article in Russian. Zh Vopr Neirokhir Im N N Burdenko. 1985;(2):24-30.

30. Marks SM, Whitwell HL, Lye RH. Recurrence of meningiomas after operation. Surg Neurol. 1986;25(5):436-440.
31. Raza SM, Gallia GL, Brem H, et al. Perioperative and long-term outcomes from the management of parasagittal meningiomas invading the superior sagittal sinus. Neurosurgery. 2010;67(4): 885-893.

32. Sughrue ME, Rutkowski MJ, Shangari G, et al. Results with judicious modern neurosurgical management of parasagittal and falcine meningiomas. Clinical article. J Neurosurg. 2011;114(3): 731-737.

33. Schulder M, Jacobs A, Carmel PW. Intraoperative MRI and adjuvant radiosurgery. Stereotact Funct Neurosurg. 2001;76(3-4):151-158.

34. Ding D, Xu Z, McNeill IT, et al. Radiosurgery for parasagittal and parafalcine meningiomas. J Neurosurg. 2013;119(4):871-877.

35. Iwai $Y$, Yamanaka K, Nakajima $H$. The treatment of skull base meningiomas-combining surgery and radiosurgery. J Clin Neurosci. 2001;8(6):528-533.

36. Kondziolka D. Radiosurgery for parasagittal and parafalcine meningiomas. J Neurosurg. 2013;119(4):869-870.

37. Santacroce A, Walier M, Régis J, et al. Long-term tumor control of benign intracranial meningiomas after radiosurgery in a series of 4565 patients. Neurosurgery. 2012;70(1):32-39.

38. Pollock BE, Stafford SL, Link MJ. Stereotactic radiosurgery of intracranial meningiomas. Neurosurg Clin N Am. 2013;24(4):499-507.

39. Subach BR, Lunsford LD, Kondziolka D, et al. Management of petroclival meningiomas by stereotactic radiosurgery. Neurosurgery. 1998;42(3):437-445.

40. Davidson L, Fishback D, Russin JJ, et al. Postoperative Gamma Knife surgery for benign meningiomas of the cranial base. Neurosurg Focus. 2007;23(4):E6.

41. Duma CM, Lunsford LD, Kondziolka D, et al. Stereotactic radiosurgery of cavernous sinus meningiomas as an addition or alternative to microsurgery. Neurosurgery. 1993;32(5):699-705.

42. Zachenhofer I, Wolfsberger S, Aichholzer M, et al. Gamma-knife radiosurgery for cranial base meningiomas: experience of tumor control, clinical course, and morbidity in a follow-up of more than 8 years. Neurosurgery. 2006;58:28-36.

43. Pinzi V, Biagioli E, Roberto A, et al. Radiosurgery for intracranial meningiomas: a systematic review and meta-analysis. Crit Rev Oncol Hematol. 2017;113:122-134.

44. Kollová A, Liscák R, Novotný J Jr, et al. Gamma Knife surgery for benign meningioma. J Neurosurg. 2007;107(2):325-336.

45. Kondziolka D, Levy El, Niranjan A, et al. Long-term outcomes after meningioma radiosurgery: physician and patient perspectives. J Neurosurg. 1999;91(1):44-50.

\section{Disclosures}

The authors report no conflict of interest concerning the materials or methods used in this study or the findings specified in this paper.

\section{Author Contributions}

Conception and design: Tuleasca, Reyns, Lejeune. Acquisition of data: Tuleasca, Leclerc. Analysis and interpretation of data: Tuleasca, Aboukais, Leclerc, Lejeune. Drafting the article: Tuleasca. Critically revising the article: Tuleasca, Vannod-Michel, Leclerc, Reyns, Lejeune. Reviewed submitted version of manuscript: Tuleasca, Aboukais, Leclerc, Reyns, Lejeune. Approved the final version of the manuscript on behalf of all authors: Tuleasca. Statistical analysis: Tuleasca. Administrative/technical/material support: Tuleasca. Study supervision: Tuleasca, Reyns, Lejeune.

\section{Correspondence}

Constantin Tuleasca: Centre Hospitalier Universitaire Vaudois, Lausanne, Switzerland. constantin.tuleasca@gmail.com; constantin.tuleasca@chuv.ch. 